MATEC Web of Conferences 6, 05001 (2013)

DOI: $10.1051 /$ matecconf/20130605001

(C) Owned by the authors, published by EDP Sciences, 2013

\title{
A coupled thermo-hygro-chemo-mechanical model for the simulation of spalling of concrete subjected to fire loading
}

\author{
M. Zeiml ${ }^{1,3}$, Y. Zhang ${ }^{2}$, C. Pichler ${ }^{3}$, R. Lackner ${ }^{3}$ and H.A. Mang ${ }^{2}$ \\ ${ }^{1}$ FCP - Fritsch, Chiari \& Partner ZT GmbH, Vienna, Austria \\ ${ }^{2}$ Institute for Mechanics of Materials and Structures (IMWS), Vienna University of \\ Technology, Vienna, Austria \\ ${ }^{3}$ Material-Technology Innsbruck (MTI), University of Innsbruck, Innsbruck, Austria
}

\begin{abstract}
The presented research work contributes to the realistic simulation of the stress state within fireloaded concrete in order to attain insight into the development and occurrence of the critical state right before and during the event of spalling. A coupled thermo-hygro-chemo-mechanical code simulating the stress state as a consequence of both thermo-hygral and thermo-mechanical processes is presented together with an embedded strong-discontinuity model which is capable of capturing and tracking the propagation of a crack evolving in concrete as a quasi-brittle material. Combination of the two mentioned models is currently under way. With the resulting coupled model, it will be possible to take into account all major couplings, allowing to realistically simulate the spalling process.
\end{abstract}

\section{INTRODUCTION}

During spalling of fire-loaded concrete, the cross-sectional area of the concrete member is reduced, seriously affecting the integrity of the structure. Spalling is mainly attributed to two types of processes: thermo-hygral and thermo-mechanical processes. Thermo-hygral processes refer to the build-up of vapor pressure inside the concrete pores. Thermo-mechanical processes refer to the thermally-induced, restrained deformation of concrete. In order to realistically assess and predict the susceptibility of a concrete structure to spalling, both types of processes need to be taken into account, making a thermohygro-chemo-mechanical approach necessary.

In this paper, the ingredients of such a model are presented, considering the main couplings between energy and mass transport as well as the mechanical behavior of fire-loaded concrete. Combining the coupled model (which gives insight into the stress evolution in heated concrete) with a code capable of simulating the crack propagation within concrete will lead to a simulation tool for simulating and predicting the spalling process in fire-loaded concrete. The presented research work aims at development of a model assisting researchers and engineers to re-analyze spalling experiments and to evaluate the efficiency of specific fire-protecting methods.

\begin{tabular}{ll}
\hline & \multicolumn{1}{c}{ LIST OF SYMBOLS } \\
\hline $\mathrm{b}^{\text {hom }}$ & Biot's coefficient acquired by multiscale homogenization [-] \\
$c_{p}$ & heat capacity of concrete $\left[\mathrm{J} \mathrm{kg}^{-1} \mathrm{~K}^{-1}\right]$ \\
$c_{p}^{g}, c_{p}^{w}, c_{p}^{s}$ & heat capacity of the gas, water, solid part of concrete $\left[\mathrm{J} \mathrm{kg}^{-1} \mathrm{~K}^{-1}\right]$ \\
$\mathbb{C}$ & elastic-stiffness tensor [Mpa] \\
$D^{\text {eff }}$ & effective diffusivity of concrete $\left[\mathrm{m}^{2} \mathrm{~s}^{-1}\right]$ \\
$f_{t}, f_{c}, f_{b}$ & tensile, compressive and biaxial compressive strength of concrete[Mpa] \\
$h$ & specific enthalpy of vaporization $\left[\mathrm{J} \mathrm{kg}{ }^{-1}\right]$
\end{tabular}

This is an Open Access article distributed under the terms of the Creative Commons Attribution License 2.0, which permits unrestricted use, distribution, and reproduction in any medium, provided the original work is properly cited. 


\section{MATEC Web of Conferences}

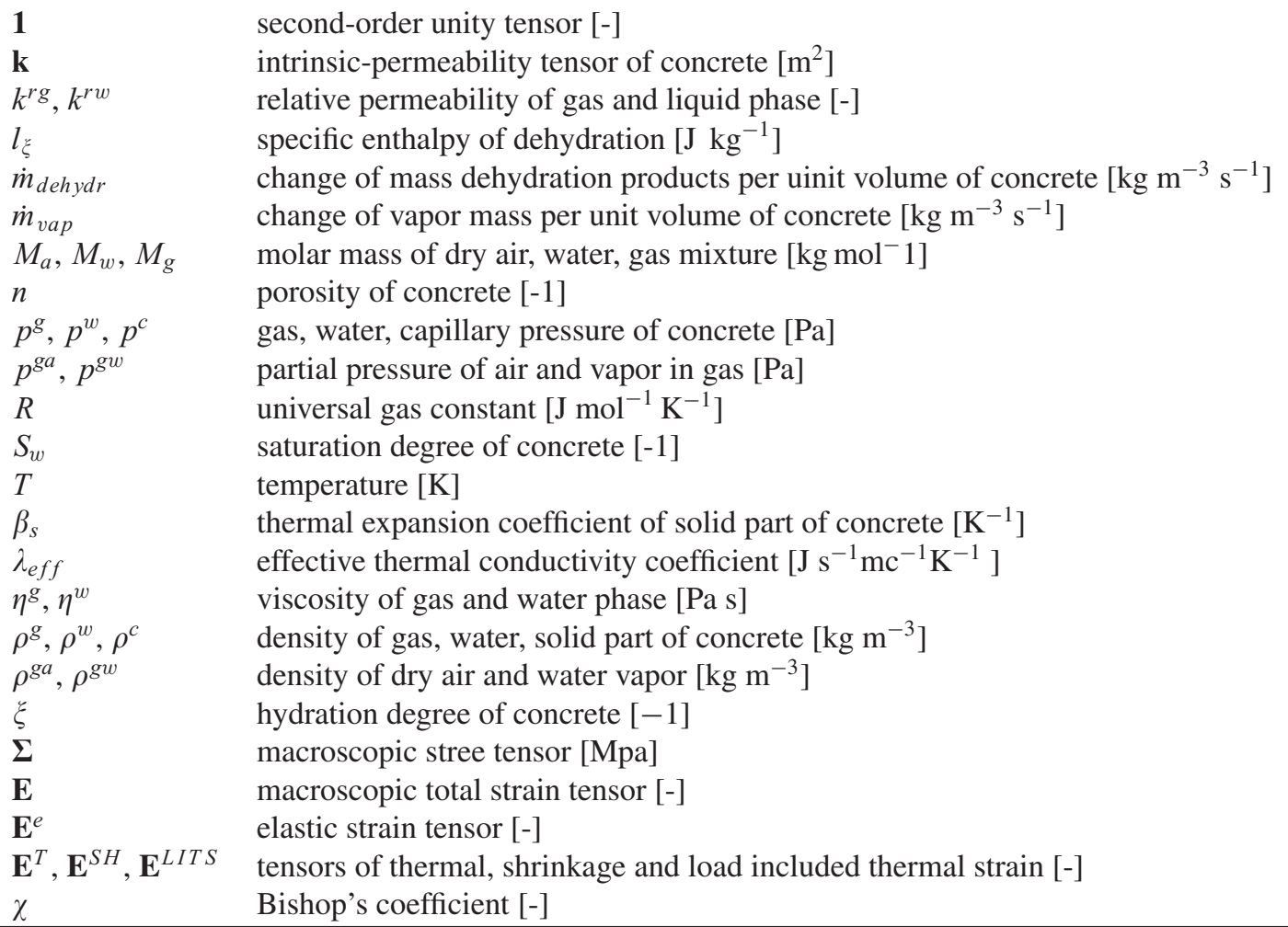

\section{THERMO-HYGRO-CHEMO-MECHANICAL MODEL}

\subsection{Thermo-hygro-chemical model}

The coupled thermo-hygro-chemical model is formulated based on the balance equations for energy and mass presented in [1].

The balance equation of the water species reads

$$
\begin{aligned}
& n\left(\rho^{w}-\rho^{g w}\right) \frac{\partial S_{w}}{\partial t}+n\left(1-S_{w}\right) \frac{\partial \rho^{g w}}{\partial t}+n S_{w} \frac{\partial \rho^{w}}{\partial t}-(1-n) \beta_{s}\left[\rho^{g w}+\left(\rho^{w}-\rho^{g w}\right) S_{w}\right] \frac{\partial T}{\partial t} \\
& -\operatorname{div}\left(\rho^{g w} \frac{\mathrm{k} k^{r g}}{\eta^{g}} \operatorname{grad} p^{g}\right)-\operatorname{div}\left(\rho^{w} \frac{\mathrm{k} k^{r w}}{\eta^{w}} \operatorname{grad} p^{w}\right)-\operatorname{div}\left[\rho^{g} \frac{M_{a} M_{w}}{M_{g}^{2}} \mathrm{D}_{\text {eff }} \operatorname{grad}\left(\frac{p^{g w}}{p^{g}}\right)\right] \\
& +\frac{(1-n)\left[\rho^{g w}\left(1-S_{w}\right)+\rho^{w} S_{w}\right]}{\rho^{s}} \frac{\partial \rho^{s}}{\partial \xi} \frac{\partial \xi}{\partial t}+\left[\rho^{g w}\left(1-S_{w}\right)+\rho^{w} S_{w}\right] \frac{\dot{m}_{\text {dehydr }}}{\rho^{s}}-\dot{m}_{\text {dehydr }}=0 .
\end{aligned}
$$

The balance equation of dry air reads

$$
\begin{aligned}
& -n \rho^{g a} \frac{\partial S_{w}}{\partial t}+n\left(1-S_{w}\right) \frac{\partial \rho^{g a}}{\partial t}-\rho^{g a}(1-n)\left(1-S_{w}\right) \beta_{s} \frac{\partial T}{\partial t}-\operatorname{div}\left(\rho^{g a} \frac{k k^{r g}}{\eta^{g}} \operatorname{grad} p^{g}\right) \\
& -\operatorname{div}\left[\rho^{g} \frac{M_{a} M_{w}}{M_{g}^{2}} D_{e f f} \operatorname{grad}\left(\frac{p^{g a}}{p^{g}}\right)\right]+\frac{(1-n) \rho^{g a}\left(1-S_{w}\right)}{\rho^{s}} \frac{\partial \rho^{s}}{\partial \xi} \frac{\partial \xi}{\partial t}+\rho^{g a}\left(1-S_{w}\right) \frac{\dot{m}_{d e h y d r}}{\rho^{s}}=0 .
\end{aligned}
$$


The balance equation of energy reads

$$
\begin{aligned}
& \left(\rho c_{p}\right)_{e f f} \frac{\partial T}{\partial t}-\operatorname{div}\left(\lambda_{e f f} \operatorname{grad} T\right) \\
& +\dot{m}_{d e h y d r} \cdot l_{\xi}^{w}+\dot{m}_{v a p} h-\left(\rho^{g} c_{p}^{g} \frac{\mathrm{k} k^{r g}}{\eta^{g}} \operatorname{grad} p^{g}+\rho^{w} c_{p}^{w} \frac{\mathrm{k} k^{r w}}{\eta^{w}} \operatorname{grad} p^{w}\right) \operatorname{grad} T=0
\end{aligned}
$$

with

$$
\begin{array}{r}
\dot{m}_{v a p}=-n \rho^{w} \frac{\partial S_{w}}{\partial t}-n S_{w} \frac{\partial \rho^{w}}{\partial t}+\rho^{w}(1-n) S_{w} \beta_{s} \frac{\partial T}{\partial t}+\operatorname{div}\left(\rho^{w} \frac{\mathrm{k} k^{r w}}{\eta^{w}} \operatorname{grad} p^{w}\right) \\
-\frac{(1-n) \rho^{w} S_{w}}{\rho^{s}} \frac{\partial \rho^{s}}{\partial T} \frac{\partial T}{\partial t}-\rho^{w} S_{w} \frac{\dot{m}_{\text {dehydr }}}{\rho^{s}}+\dot{m}_{\text {deh } y d r} .
\end{array}
$$

Detailed information on the material parameters and their evolution with temperature can be found in $[1,2]$.

\subsection{Effective-stress model}

The isothermal macroscopic effective-stress theory [3, 4] can be described as

$$
\boldsymbol{\Sigma}=\mathbb{C}: \mathbf{E}^{\mathrm{e}}-\mathbf{1} \mathrm{b}\left(p^{g}-\chi p^{c}\right)
$$

where the Biot's coefficient b can be acquired by, e.g., multiscale homogenization (see [5] for details]. The Bishop's coefficient $\chi$ can be defined as a function of the saturation degree $S_{w}$. In heated concrete, Eq. (4) is reformulated, considering the shrinkage strain $\mathbf{E}^{\mathrm{SH}}$ according to [6], leading to

$$
\left.\boldsymbol{\Sigma}=\mathbb{C}: \mathbf{E}-\mathbf{E}^{\mathrm{SH}}-\mathbf{E}^{\mathrm{T}}-\mathbf{E}^{\mathrm{LITS}}\right)-\mathbf{1} \mathrm{b}^{\text {hom }} p^{g},
$$

where $\mathbf{E}^{\mathrm{T}}$ is the thermal strain tensor and $\mathbf{E}^{\mathrm{LITS}}$ represents the strain appearing in concrete subjected to combined mechanical and thermal loading. Based on the approach presented in [7], a relationship between $\mathbf{E}^{\text {LITS }}$ and $\boldsymbol{\Sigma}$ is given in [8, 9]], reading

$$
\mathbf{E}^{\text {LITS }}=k^{\text {LITS }} \frac{\boldsymbol{\Sigma}}{f_{c}(T)} \frac{\operatorname{Tr}\left(\mathbf{E}^{\mathrm{T}}\right)}{3}
$$

where $k^{L I T S}=0.6$ was considered within the numerical simulation. A comparison between simulation and experimental results is shown in Figure 1 (see $[8,9]$ for details.

\subsection{Tensile strength under biaxial compression}

Considering a concrete block, fire loading of one surface leads to biaxial compressive loading near the surface, causing a decrease of the tensile strength along the direction perpendicular to the heated surface. This can be considered by, e.g., a linear reduction of the temperature-dependent tensile strength as a function of the above mentioned compressive loading (see Figure 2 and [2]).

\section{NUMERICAL EXAMPLE}

\subsection{Model and material parameters}

For the numerical investigation of spalling, a concrete member heated from one side was simulated using a 2D axisymmetric model (see Figure 3 ). The minimum element size was approximately $1 \mathrm{~mm}$. The fire load was considered to increase linearly from $20^{\circ} \mathrm{C}$ to $1200^{\circ} \mathrm{C}$ within the first $300 \mathrm{~s}$. After that, it was 


\section{MATEC Web of Conferences}
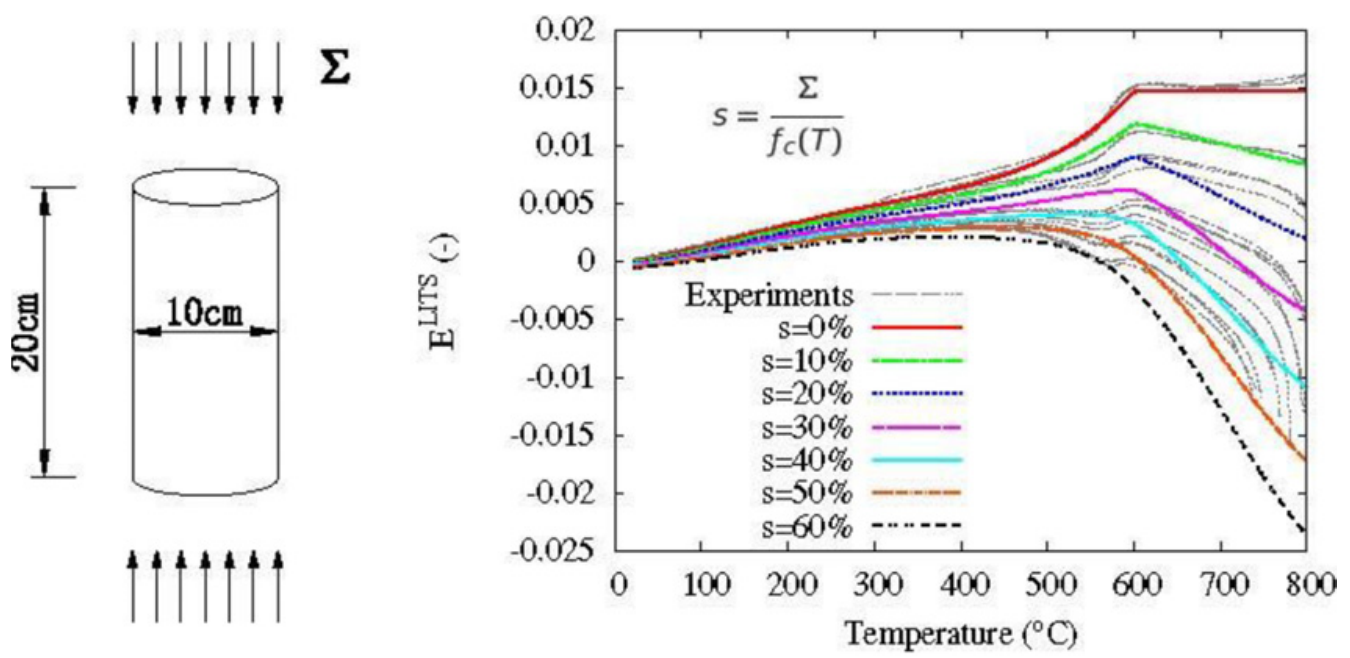

Figure 1. Comparison of numerical results for $\mathbf{E}^{\text {LITS }}$ with experimental data (see $[8,9]$ for details).
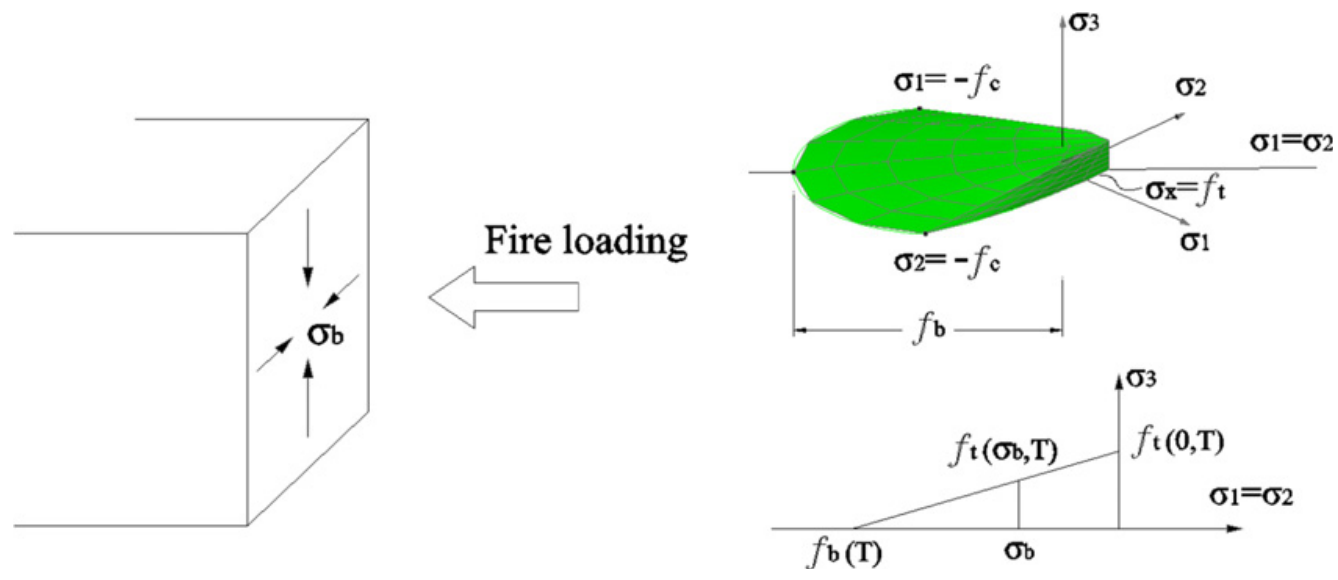

Figure 2. Reduction of the tensile strength $f_{t}\left(\sigma_{b}, T\right)$ in case of thermal loading from the surface.

set constant at $1200^{\circ} \mathrm{C}$. The material parameters at room temperature are shown in Table 1, information on the temperature-dependent functions for the respective material parameters can be found in [10]. The intrinsic permeability $\mathbf{k}$ was varied in order to perform a parameter study (see Table 1).

\subsection{Results}

Figures 4 and 5 show selected numerical results for $t=200 \mathrm{~s}$ and $t=300 \mathrm{~s}$. Hereby, the effective stress perpendicular to the heated surface (y-direction, see Fig. 3), which can be calculated by $\sigma=(\mathbf{v} \otimes \mathbf{v}):\left(\Sigma+\mathrm{b}^{\text {hom }} p^{g}\right)$ with $\mathbf{v}=(0,1) . \sigma$ was compared with the temperature-dependent tensile strength $f_{t}$ under biaxial compression in order to obtain indications for the initiation of spalling. The results of $\sigma$ and $f_{t}$ are shown together with the gas pressure $p^{g}$. The numerical values for gas pressure $p^{g}$ are well in the range of experimental values obtained under comparable test parameters (concrete mix, heating curve etc.), see $[11,12]$ for details. 

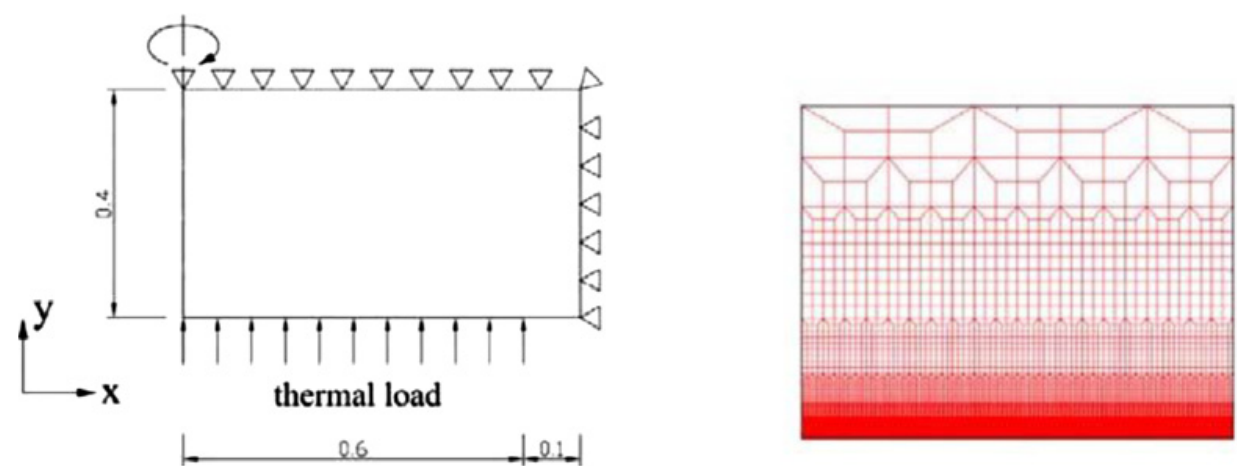

Figure 3. Axisymmetric model and finite-element discretization used for numerical simulation (dimensions in $\mathrm{m}$ ).

Table 1. Material parameters (values at room temperature).

\begin{tabular}{lll}
\hline Elastic modulud $E$ & {$[\mathrm{GPa}]$} & 31.5 \\
Tensile strength $f_{t}$ & {$[\mathrm{MPa}]$} & 1.67 \\
Intrinsic permeability k & {$\left[\mathrm{m}^{2}\right]$} & $10^{-17}, 10^{-18}$ \\
Initial saturation degree $S_{w}$ & {$[-]$} & 0.4 \\
Thermal expansion coefficient $\beta_{s}$ & {$[1 / \mathrm{K}]$} & $3.6 \cdot 10^{-5}$ \\
Thermal conductivity $\lambda$ & {$[\mathrm{W} /(\mathrm{m} \mathrm{K})]$} & 1.9 \\
Specific Heat $c_{p}$ & {$[\mathrm{~J} /(\mathrm{kg} \mathrm{K})]$} & 900 \\
Initial porosity $n$ & {$[-]$} & 0.1 \\
Density $\rho_{s}$ & {$\left[\mathrm{~kg} / \mathrm{m}^{3}\right]$} & 2400 \\
\hline
\end{tabular}

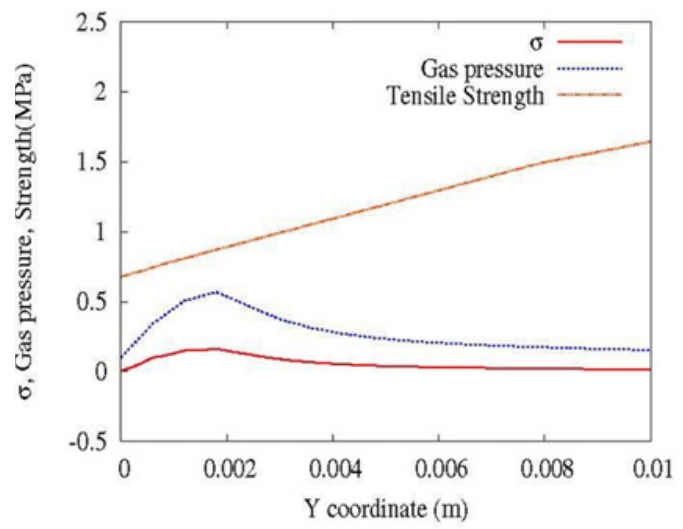

(a)

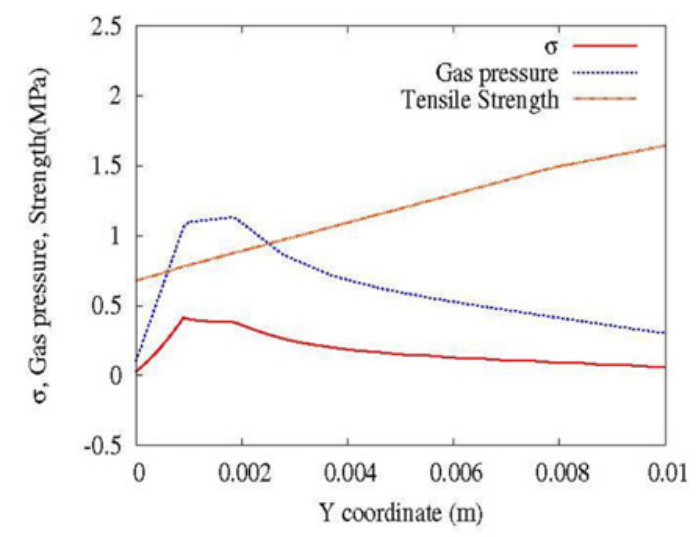

(b)

Figure 4. Simulation results at $t=200 \mathrm{~s}$ : (a) $\mathbf{k}=10^{-17} \mathrm{~m}^{2}$, (b) $\mathbf{k}=10^{-18} \mathrm{~m}^{2}$.

The numerically-obtained distributions of gas pressure $p^{g}$ and stress $\sigma$ perpendicular to the heated surface are of similar shape, resulting from the underlying thermo-hygral processes (gas pressure influencing the mechanical stresses). Comparison of the results obtained with different values for the intrinsic permeability $\mathbf{k}$ (see Figs. 4 and 5) shows that $\sigma$ increases considerably with decreasing $\mathbf{k}$. On the other hand, the tensile strength $f_{t}$ perpendicular to the heated surface is reduced by the combination of increasing temperature and biaxial compression, reflecting the underlying 


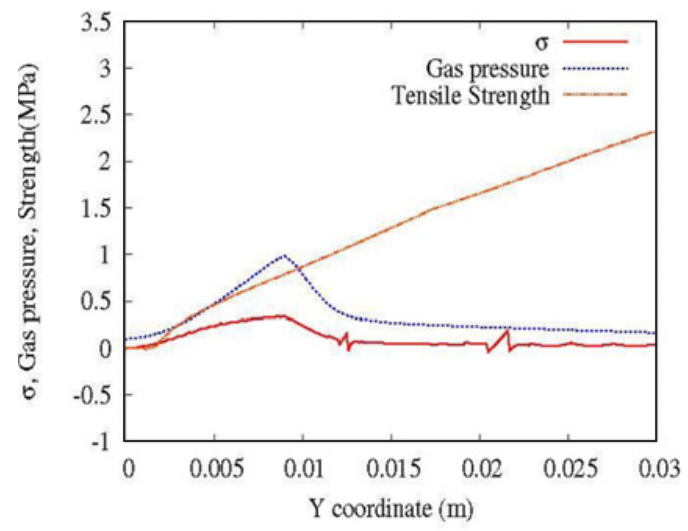

(a)

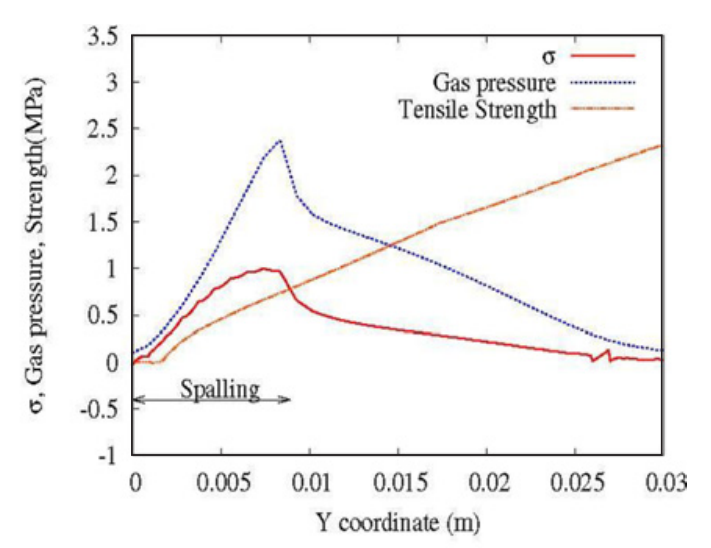

(b)

Figure 5. Simulation results at $t=300 \mathrm{~s}$ : (a) $\mathbf{k}=10^{-17} \mathrm{~m}^{2}$, (b) $\mathbf{k}=10^{-18} \mathrm{~m}^{2}$.

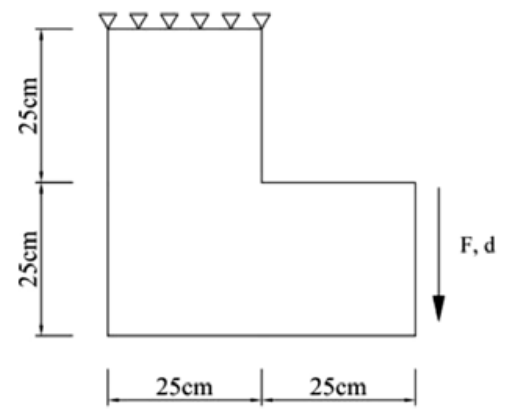

$$
\begin{aligned}
& E=25.85 \mathrm{GPa} \\
& \nu=0.18 \\
& \mathrm{G}_{f}=95 \mathrm{~N} / \mathrm{m} \\
& f_{t}=2.7 \mathrm{MPa} \\
& \beta=1 \\
& \text { thickness }=10 \mathrm{~cm}
\end{aligned}
$$

Figure 6. L-shaped panel test: geometric properties and material parameters as shown in [16].

thermo-mechanical processes. Hence, both types of processes considered to be responsible for spalling are captured by the presented model. Considering the simulation results, no spalling is predicted in simulation (a) with $\mathbf{k}=10^{-17} \mathrm{~m}^{2}$, but the numerical results indicate that spalling may occur in simulation (b) with $\mathbf{k}=10^{-18} \mathrm{~m}^{2}$ at $300 \mathrm{~s}$.

\section{SIMULATION OF CRACK PROPAGATION}

For simulation of the fracturing process during spalling, the strong-discontinuity embedded approach (SDA) presented in [13] will be implemented into the simulation tool. For this purpose, the energybased crack-tracking strategy presented in [14] is modified by the authors to be incorporated into the SDA (see [15] for details). For validation purposes, numerical examples of (i) an L-shaped panel and (ii) a pull-out test in isothermal conditions were simulated, showing the applicability of the used model.

The geometric dimensions and the material parameters as well as the loading and boundary conditions of the L-shaped panel, experimentally investigated in [16], are shown in Figure 6. The numerically-obtained force-displacement curve and crack path are shown in Figure 7.

Within simulation of the pull-out test, a 2D axisymmetric analysis was performed (see Fig. 8). As pointed out in [17], the pull-out test has two types of possible failure modes: tensile failure and compressive failure. In the presented benchmark, only tensile failure was considered. 

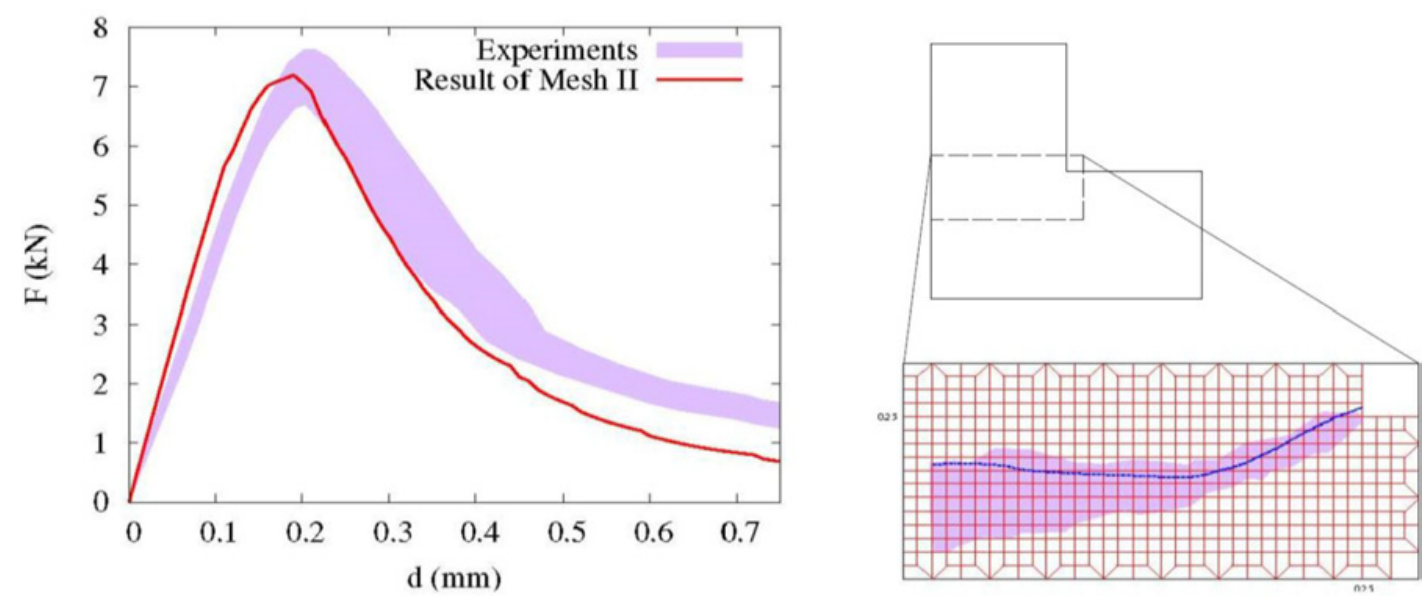

Figure 7. L-shaped panel test: comparison of numerically-obtained force-displacement curve and crack path with experimentally-obtained results presented in [16].

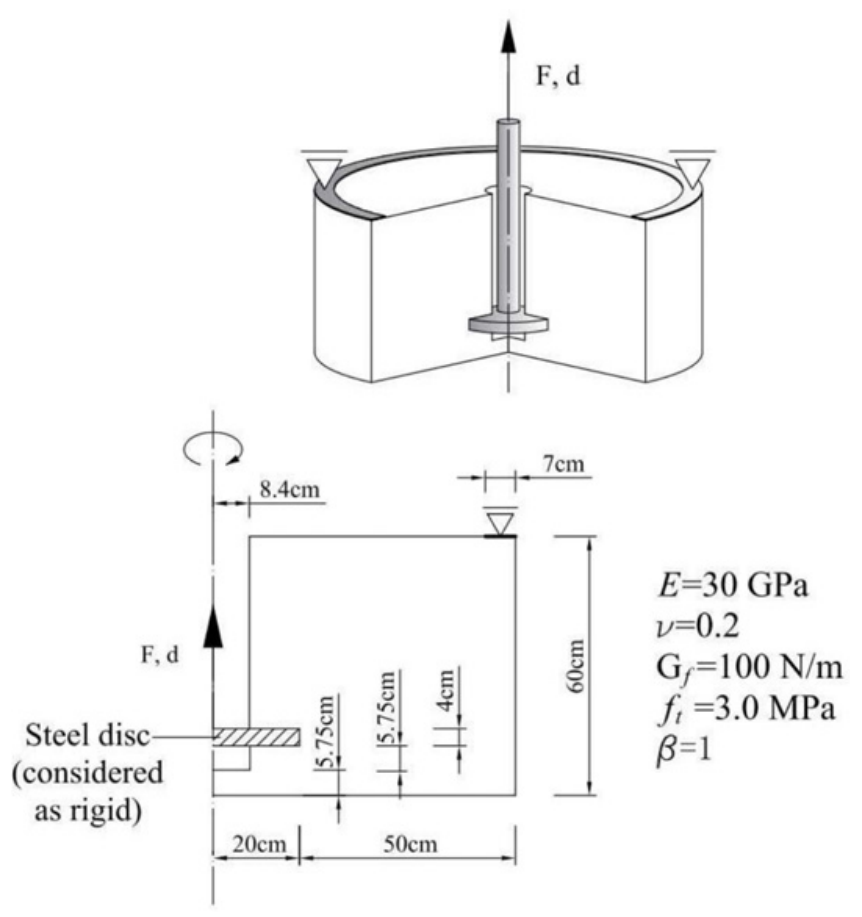

Figure 8. Pull-out test: geometric properties and material parameters as shown in [18, 19].

The numerically-obtained load-displacement curve is shown in Figure 9. Since other papers (see $[18,19])$ considered one quarter of the structure, F/4 is shown in the force-displacement curve. Good agreement is observed between the results obtained by the authors and numerical results from other simulations. The observed good performance of the developed model leads to the conclusion that the chosen simulation tool for crack propagation is capable of simulating the fracturing process during spalling. 


\section{MATEC Web of Conferences}
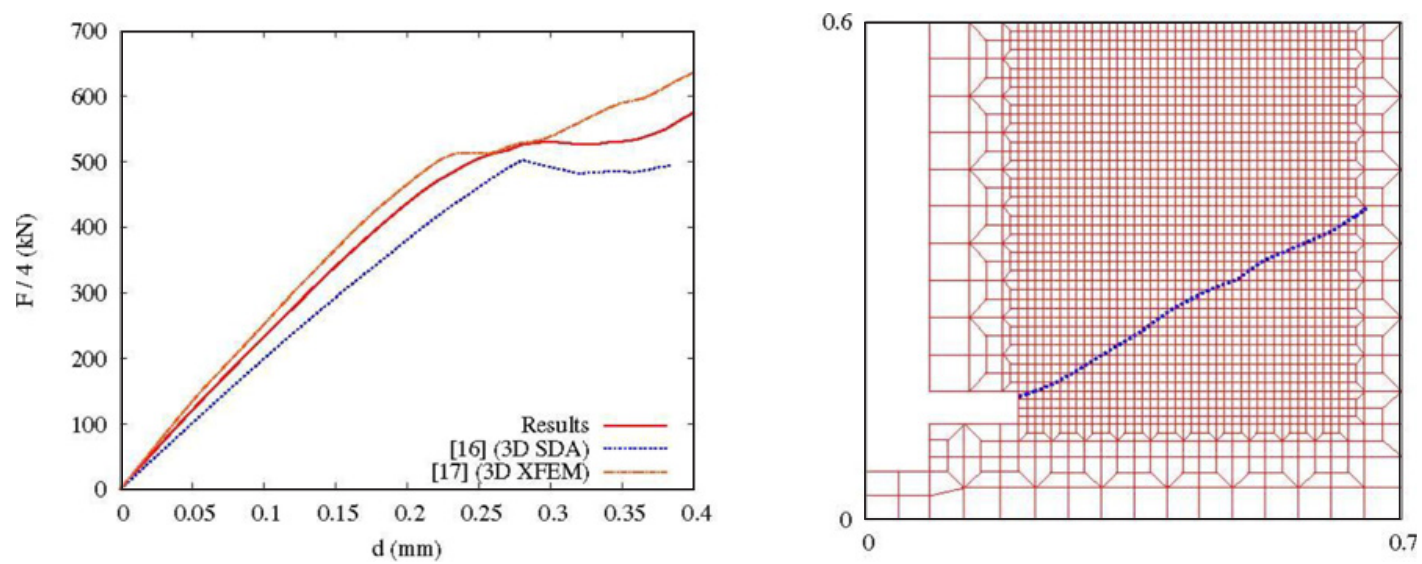

Figure 9. Pull-out test: comparison of numerically-obtained force-displacement curve and crack path with numerical results reported in $[18,19]$.

\section{CONCLUSIONS AND ONGOING WORK}

In this paper, the ingredients of a coupled thermo-hygro-chemo-mechanical model for simulating the stress evolution within fire-loaded concrete were presented. Hereby, thermo-hygral as well as thermomechanical processes were taken into account, since both types of processes are considered to contribute to spalling. The envisioned model shall be able to simulate the stress state in heated concrete right before and during the spalling process considering all relevant processes.

Preliminary numerical results obtained with the thermo-hygro-chemo-mechanical model illustrated the contribution of both above-mentioned processes to the concrete's susceptibility to spalling. Thermohygral processes cause an increase in pore pressure in consequence of vaporization of pore water. Subsequently, the (effective) tensile stresses in the concrete matrix are considerably increased. Parameter studies showed that these tensile stresses increase with decreasing permeability of concrete, since less water vapor is able to escape the pore system. Thermo-mechanical processes, on the other hand, cause a build-up of compressive stresses parallel to the heated surface, leading to a decrease of the tensile strength perpendicular to the heated surface. This was considered by introducing a dependency of the (temperature-dependent) out-of-plane tensile strength on the biaxial in-plane compressive stresses. The numerical examples showed the increased spalling risk of concrete with low permeability.

Currently, the presented thermo-hygro-chemo-mechanical model is extended to the simulation of the cracking process initiating spalling. For this purpose, a strong-discontinuity approach was adopted and validated by re-analysis of experiments as well as numerical studies of other research groups. Once the presented approach is implemented in the model, it will be possible to simulate crack propagation during the spalling event. This will enable for consideration of the effect of cracking on the pressure within the concrete's pore space as well as transport of water vapor towards and within the opening crack.

Finally, the developed code will enable for simulation of the main couplings between energy/mass transport and the mechanical loading situation within fire-loaded concrete, yielding realistic simulation of the stress state right before and during the spalling of near-surface concrete layers. This will enable researchers and engineers to re-analyze spalling experiments and to evaluate the safety of concrete and concrete structures under fire loading and the efficiency of fire-protecting methods. 
This research was conducted with financial support by the Austrian Ministry for Transport, Innovation and Technology (bm.vit) within the KIRAS-project (Austrian security research program) 836268 "Sicherheit von Hohlraumbauten unter Feuerlast" ("Safety of underground structures under fire loading").

\section{References}

[1] D. Gawin, F. Pesavento, and B. Schrefler, "Modelling of hygro-thermal behaviour of concrete at high temperature with thermo-chemical and mechanical material degradation", Computer Methods in Applied Mechanics and Engineering, vol. 192, pp. 1731-1771, 2003.

[2] M. Zeiml, R. Lackner, F. Pesavento, and B. Schrefler, "Thermo-hydro-chemical couplings considered in safety assessment of shallow tunnels subjected to fire load", Fire Safety Journal, vol. 43, pp. 83-95, 2008.

[3] B. Schrefler and D. Gawin, "The effective stress principle: Incremental or finite form?", International Journal for Numerical and Analytical Methods in Geomechanics, vol. 20, pp. 785-814, 1996.

[4] L. Dormieux, D. Kondo, and F.-J. Ulm, Microporomechanics. John Wiley \& Sons, 1st ed., June 2006.

[5] Y. Zhang, C. Pichler, Y. Yuan, M. Zeiml, and R. Lackner, "Micromechanics-based multifield framework for early-age concrete", Engineering Structures, vol. 47, pp. 16-24, 2013.

[6] D. Gawin, F. Pesavento, and B. Schrefler, "Modelling of deformations of high strength concrete at elevated temperatures", Materials and Structures, vol. 37, pp. 218-236, May 2004.

[7] S. Thelandersson, "Modeling of combined thermal and mechanical action in concrete", Journal of Engineering Mechanics (ASCE), vol. 113, no. 6, pp. 893-906, 1987.

[8] T. Ring, M. Zeiml, R. Lackner, and J. Eberhardsteiner, "Experimental investigation of strain behavior of heated cement paste and concrete", Strain. In print, 2013.

[9] T. Ring, M. Zeiml, R. Lackner, "Thermo-mechanical behavior of concrete at high temperature: From micromechanical modeling towards tunnel safety assessment in case of fire", In: Computational Engineering, G. Hofstetter (Ed.), Springer, Vienna. In print, 2013.

[10] M. Zeiml, Concrete subjected to fire loading — From experimental investigation of spalling and mass-transport properties to structural safety assessment of tunnel linings under fire. $\mathrm{PhD}$ thesis, Vienna University of Technology, Vienna, Austria, 2008.

[11] R. Jansson, L. Boström, "The influence of pressure in the pore system on fire spalling of concrete", Fire Technology, vol. 46, pp. 217-230, 2010.

[12] J.-C. Mindeguia, P. Pimienta, H. Carréc, C. La Borderiec, "Experimental analysis of concrete spalling due to fire exposure", European Journal of Environmental and Civil Engineering, DOI:10.1080/19648189.2013.786245, In print, 2013.

[13] J. Mosler and G. Meschke, "3D modelling of strong discontinuities in elastoplastic solids: fixed and rotating localization formulations", International Journal for Numerical Methods in Engineering, vol. 57, pp. 1553-1576, 2003.

[14] G. Meschke and P. Dumstorff, "Energy-based modeling of cohesive and cohesionless cracks via X-FEM", Computer Methods in Applied Mechanics and Engineering, vol. 196, pp. 2338-2357, 2007.

[15] Y. Zhang, R. Lackner, M. Zeiml, "Strong discontinuity approach in high-order element: Energybased crack-tracking strategy and validations". In preparation, 2013.

[16] B. Winkler, G. Hofstetter, and H. Lehar, "Application of a constitutive model for concrete to the analysis of a precast segmental tunnel lining," International Journal for Numerical and Analytical Methods in Geomechanics, vol. 28, pp. 797-819, 2004.

[17] J. Rots, Computational Modeling of Concrete Fracture. PhD thesis, Delft University of Technology, Delft, The Netherlands, 1988. 


\section{MATEC Web of Conferences}

[18] C. Feist and G. Hofstetter, "Three-dimensional fracture simulations based on the SDA," International Journal for Numerical and Analytical Methods in Geomechanics, vol. 31, pp. 189-212, 2007.

[19] T. C. Gasser and G. A. Holzapfel, "Modeling 3D crack propagation in unreinforced concrete using PUFEM," Computer Methods in Applied Mechanics and Engineering, no. 194, pp. 2859-2896, 2005. 